\title{
Exploring the scope of nanoparticles for arsenic removal in groundwater
}

\author{
A. Kumar ${ }^{1}$, H. Joshi ${ }^{1}$ \& A. Kumar ${ }^{2}$ \\ ${ }^{1}$ Department of Hydrology, Indian Institute of Technology, Roorkee, India \\ ${ }^{2}$ Department of Chemistry, Indian Institute of Technology, Roorkee, India
}

\begin{abstract}
Nanoadsorbents have gained considerable attention for arsenic removal in groundwater among scientific communities from last decade. Nanotechnology based water treatment systems are logical choice in respect to resource and energy efficiency. The literature is widely replete in cases of development of different nanoadsorbents which are explored for arsenic removal. Among these, nanoscale zero-valent iron has been observed extensively employed both at laboratory and pilot scale studies due to its strong affinity, easy availability and environmental friendly nature. Its unstable nature limits the application at large scale efficiently. In present study, $\gamma-\mathrm{Fe}_{2} \mathrm{O}_{3}$ nanoparticles were evaluated for arsenic removal using Taguchi's design of experimental methodology for real world water conditions by formulating artificial groundwater.
\end{abstract}

\section{INTRODUCTION}

Arsenic removal from groundwater is a great concern among the scientific communities due to its potential health impacts. Both developed and developing countries are under a potential threat of its groundwater contamination. Among the several treatment technologies, adsorption has been reported to be viable due to its easy operational processes. It is therefore, different types of conventional adsorbents have been widely employed in the removal of arsenic from groundwater.

In past two decades, several metallic nanoadsorbents including oxides of $\mathrm{Fe}, \mathrm{Al}, \mathrm{Ce}, \mathrm{Cu}, \mathrm{Zr}$, Ti have been developed for arsenic removal. The metallic iron based nanoadsorbents have been widely explored due to their strong affinity towards arsenic and ecological-friendly nature. Among various polymorphs, nZVI (zero-valent iron) has been extensively explored in the literature both at laboratory and pilot scale studies. These NPs are unstable in natural environmental conditions and prone to oxidize into iron oxides/hydroxides after oxidation which limit its application for pilot scale studies significantly. However, these nanoparticles have gained notable attention for pilot scale studies in developed countries.

The aim of present study is to synthesize the stable polymorph of $\mathrm{Fe}^{(\mathrm{III})}$ oxide $\left(\gamma-\mathrm{Fe}_{2} \mathrm{O}_{3}\right) \mathrm{NPs}$ and their evaluation for the possible scope of in situ sequestration of arsenic. These nanoparticles were explored for the real-world water conditions. The samples were collected from two locations of district Ballia, Uttar-Pradesh, India. The laboratory scale experiments are not feasible using actual groundwater due to requirement of large samples volume and fluctuating quality issues. Therefore, a computational analysis using mathematical matrix was exercised in calculating the required quantity of available salt compounds for synthesis of artificial groundwater (Adams 1998). Taguchi's methodology (Design Expert 7.0.0) was adopted for experimental design which investigate effect of different parameters on the mean and variance of performance characteristics.

\section{METHODS/EXPERIMENTAL}

\subsection{Synthesis of $\gamma-\mathrm{Fe}_{2} \mathrm{O}_{3}$ nanoparticles and characterization techniques}

The $\gamma-\mathrm{Fe}_{2} \mathrm{O}_{3}$ NPs used in this study were synthesized following a procedure adapted from (Kaloti \& Kumar 2016) with few notable deviations. Phase identification was examined using XRD pattern which further confirmed through RAMAN spectrum. The surface morphology, charge and functionalities were explored through SEM/HRTEM, zeta potential and FTIR analysis.

\subsection{Taguchi's methodology and artificial groundwater formulation}

Taguchi's methodology is an effective statistical tool in developing a suitable approach for laboratory investigations at optimized parametric levels. It depends on modeling of experiments classifying the engineering aspects for the cost-effectiveness of process along with to overcome drawbacks related to conventional removal techniques. The orthogonal arrays (OAs), S: $\mathrm{N}$ analysis and variance are expressed as significant tools to analyze the outcomes of parameter design.

In this study, the calculated degree of freedom is $26[=$ no. of parameters $(7) \times\{$ no. of levels $(3)-1\}+\{$ no. of two-PI $(3) \times$ no. of PI $(2) \times$ no. of 
Table 1. Process parameters for experimental design using Taguchi's orthogonal array (OAs) of methodology.

\begin{tabular}{llrcc}
\hline & Parameters & level 1 & level 2 & level 3 \\
\hline A & Arsenic conc. $\left(\mu \mathrm{g} \mathrm{L}^{-1}\right)$ & 55 & 127.5 & 200 \\
$\mathrm{~B}$ & TDS $\left(\mathrm{mg} \mathrm{L}^{-1}\right)$ & 350 & 900 & 1450 \\
$\mathrm{C}$ & Shaking speed $(\mathrm{rpm})$ & 100 & 170 & 240 \\
$\mathrm{D}$ & Temp. $\left({ }^{\circ} \mathrm{C}\right)$ & 10 & 20 & 30 \\
E & pH & 7 & 8 & 9 \\
F & Dose $\left(\mathrm{g} \mathrm{L}^{-1}\right)$ & 0.05 & 0.10 & 0.15 \\
G & Contact time $(\mathrm{min})$ & 2 & 53 & 104 \\
\hline
\end{tabular}

columns assigned for each PI (2) \}]. Hence, a standard three level OA of $\mathrm{L}_{27}\left(3^{13}\right)$ was selected for investigation. The details of experimental parameters are shown in Table 1. In groundwater formulation, a multiplication of inverse matrix with the targeted values of concentration was done to calculate the number of compounds required to achieve the desired element concentration in formulation of water.

The formulation array was customized by varying the compounds containing common ions and arrangement of array to goal the appropriate results.

\section{RESULTS AND DISCUSSION}

\subsection{Physio-chemical characteristics of NPs}

The nanoparticles were found to be polycrystalline in nature. The diffraction patterns match with the reflections which correspond to cubic structure of $\gamma-\mathrm{Fe}_{2} \mathrm{O}_{3}$ (JCPDS file no. 39-1346). Using Debye-Scherrer's equation, the average crystallite size of iron oxide NPs was calculated to be $14.61 \pm 2.43 \mathrm{~nm}$ In FTIR spectra, presence of large surface hydroxyl moieties was observed. The average particle size $(\mathrm{nm})$ distribution for these analyses were calculated to be $57.92 \pm 15.51$ and $15.72 \pm 8.15$, respectively. The large value of calculated average particle size during FESEM analysis indicates formation of agglomerates which occur due to the magnetic properties these NPs. However, a significant agreement between the calculated average particle size using XRD and HRTEM techniques was observed which validate the analysis of results obtained. The $\zeta$-potential for these nanoparticles was observed in acidic range $\left(\mathrm{pH}_{\mathrm{pzc}} \sim 2.3\right)$.

\subsection{Effect of process parameters}

Low temperature favors removal capacity indicates process of physisorption. Maximum shaking speed is affecting the adsorption capacity of the nanoparticles which might be due to the desorption of adsorbed As(V) into the aqueous solution (Fig. 1). Further, the maximum value of $\mathrm{q}_{\mathrm{e}}$ is observed at the larger value of contact time $\left(\mathrm{L}_{3}\right)$ showing that the $\mathrm{As}(\mathrm{V})$ oxyanions and hydroxyl groups of nanoparticles are interacting with the weak electrostatic forces. A shift for the parameter (C) (one place) towards the higher value

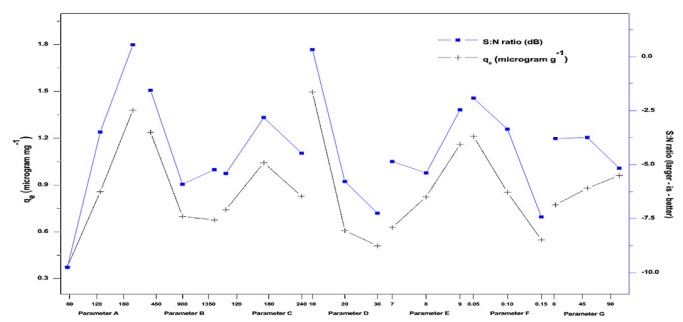

Figure 1. Response curve showing interaction between the process parameters in multi-ionic system for $\mathrm{As}(\mathrm{V})$ removal onto $\gamma-\mathrm{Fe}_{2} \mathrm{O}_{3}$ nanoparticles.

showing that the adsorption is occurring through weak electrostatic interaction which needs to care of in field scale application of these nanoparticles.

$$
\begin{aligned}
& \mathrm{Fe}-\mathrm{O}-\mathrm{H}+\mathrm{H}^{+} \stackrel{p H<p H_{P Z C}}{\longrightarrow} \mathrm{Fe}-\mathrm{O}^{+} \mathrm{H}_{2}(\mathrm{pH}<6.1) \\
& \mathrm{Fe}-\mathrm{O}-\mathrm{H}+\mathrm{OH}^{-} \stackrel{p H>p H_{P Z C}}{\longrightarrow} \mathrm{Fe}-\mathrm{O}^{-}+\mathrm{H}_{2} \mathrm{O} \quad\left(\mathrm{pH}_{7}-9\right) \\
& \mathrm{Fe}-\mathrm{O}-\mathrm{H}+\mathrm{H}^{+}+2(\mathrm{H}-\mathrm{OH}) \stackrel{\mathrm{pH}>\mathrm{PH}_{P Z C}}{\longrightarrow} \mathrm{Fe}-\mathrm{O}^{-}+2 \mathrm{H}_{3} \mathrm{O}^{+}(\mathrm{pH} 6.1-7.0)
\end{aligned}
$$

The $\mathrm{q}_{\mathrm{e}}$ value is increased as contaminant concentration increases which is due to a decrease in the hindrance for the uptake of $\mathrm{As}(\mathrm{V})$ as the masstransfer operating force increased. This small variation explains that ions in solution are providing extra sites for adsorption by acting as counter ion providing which led to increase in the $\mathrm{q}_{\mathrm{e}}$ value. As few authors have been reported the increase in removal capacity of nanoparticles in the presence of ions such as Nitrate and bicarbonates.

\section{CONCLUSIONS}

The environmental stable $\gamma-\mathrm{Fe}_{2} \mathrm{O}_{3}$ NPs were found efficient in removal of arsenic. Investigations using PHREEQ in exploring the formation of chemical process, surface complexation and mineral precipitation reactions are desirable for futuristic studies.

\section{ACKNOWLEDGEMENT}

This work is supported by University Grant Commission (UGC), New Delhi, India by providing financial assistance in the form of research fellowship under Grant Number 7411-29-061-429.

\section{REFERENCES}

Adams, G. \& Bubucis, P.M. 1998. Calculating an artificial sea water formulation using spreadsheet matrices. Aquarium Sci. Conserv. 2(1): 35-41.

Kaloti, M. \& Kumar, A. 2016. Synthesis of chitosan-mediated silver coated $\gamma-\mathrm{Fe}_{2} \mathrm{O}_{3}\left(\mathrm{Ag}-\gamma-\mathrm{Fe}_{2} \mathrm{O}_{3} @ \mathrm{Cs}\right)$ superparamagnetic binary nanohybrids for multifunctional applications. J. Phys. Chem. C 120(31): 17627-17644. 